\title{
Exploring and developing a shared understanding of the issues surrounding engineering mathematics
}

\author{
J. BILBAO ${ }^{1}$, E. BRAVO ${ }^{1}$, O. GARCÍA ${ }^{1}$, C. REBOLLAR ${ }^{1}$, C. VARELA ${ }^{1}$, A. UUKKIVI $^{2}$, O. $^{2}$ \\ LABANOVA $^{2}$, M. LATÕNINA ${ }^{2}$, E. SAFIULINA ${ }^{2}$, A. CELLMER ${ }^{3}$, J. CYMERMAN $^{3}$, IGOR \\ KIERKOSZ ${ }^{3}$, K. BROWN ${ }^{4}$, G. KELLY ${ }^{4}$, A.P. LOPES ${ }^{5}$, F. SOARES ${ }^{5}$, C. FENISER ${ }^{6}$, V.

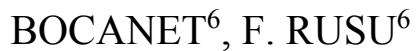 \\ ${ }^{1}$ University of the Basque Country UPV/EHU, ${ }^{2}$ TTK University of Applied Sciences, ${ }^{3}$ Koszalin \\ University of Technology, ${ }^{4}$ Letterkenny Institute of Technology, ${ }^{5}$ Polytechnic of Porto (P. Porto) / \\ ISCAP - CEOS.PP, ${ }^{6}$ Technical University of Cluj Napoca \\ ${ }^{1}$ SPAIN, ${ }^{2}$ ESTONIA, ${ }^{3}$ POLAND, ${ }^{4}$ IRELAND, ${ }^{5}$ PORTUGAL, ${ }^{6}$ ROMANIA \\ javier.bilbao@ehu.eus
}

\begin{abstract}
Although Mathematics is a pillar which many of the subjects of any Engineering degree are based on, and in spite of being used as a tool in almost all of such subjects, it is sometimes difficult for students to assimilate the mathematical concepts. Since this relationship between Engineering and Mathematics is unavoidable, a consortium of universities from different countries is working on a project, EngiMath, to, on the one hand, make it easier for teachers to teach Mathematics in the first years of Engineering degrees; and, on the other hand, to promote study from a "student-centric" point of view. As a previous step to the development of educational material that fulfills these purposes, a study of the students' feelings about Mathematics and their experience in studying them has been carried out.
\end{abstract}

Key-Words: - Information Theory and Applications, Computer Science, Erasmus + Projects, Mathematics Curricula, Higher Education, Engineering Education, Teaching Methods, Web-based Education, Learning Objectives, Math Skills, Educational Experiences

Received: September 18, 2019. Revised: March 5, 2020. Accepted: March 10, 2020. Published: March 31, 2020.

\section{Introduction}

Until not many years ago, it was common for research on the teaching-learning of any area of knowledge, including mathematics, to focus on cognitive processes, or how a student is able to capture, encode, store and work with the information that is normally transferred to him or her by the teacher. But in this process there are other factors that also influence, such as motivational, affective, metacognitive, evolutionary and social factors, which can have their importance in the context of education [1]. Focusing on Mathematics related subjects in Higher Education, their teaching has sometimes been done through algorithmic procedures often decontextualized from real applications and their relationship with other subjects. Moreover, in this process in which its applicability in everyday life has not been taken into account, formulas learned by heart have been used [2] with little relation to their real application. In these cases, it is common for students to replicate what they have seen in class, without a clear idea of why or what for, and without knowing very well what to do in the case of small variations in the types of problems posed in class. We could say that the students have learned the concepts, but only to apply them in situations equal to those created by the teacher. This is one of the reasons why the contents may lack real meaning for these students. Likewise, there are places in which results are prioritized without concern for the mental processes that the student develops when solving mathematical exercises or problems [3]. However, other authors claim that, in order for the teaching to be meaningful, and also for the student to learn to learn and learn to think, this student must be the protagonist of his or her own knowledge in a 
conscious and reflective way [4], and include problem solving as a skill that should have an important place in his or her teaching-learning process [5]. Other authors mention Computational Thinking as a valid help option in this teachinglearning process [6].

According to Osses and Jaramillo [7], learning is only generated when the tasks are related in a convenient way, the subject decides to learn, relates the concepts and gives them a sense from the conceptual structure he already has. In other words, when the student builds new knowledge from those already acquired, but, in addition, builds them because he is interested in doing so.

From its beginnings, engineering has had strong connections with the so-called Science subjects in general and with Mathematics in particular, the latter being a fundamental tool in the whole diverse range of analysis and calculation processes that an engineer must carry out. Likewise, in recent years, the idea that Mathematics is a tool through which we model and respond to real problems has been increasingly promoted, creating degrees of Mathematical Engineering in some universities.

However, such problems can correspond to a very complex nature, even presenting difficult challenges for an engineer, with the training he usually has. By this, we mean problems of a nondeterministic nature, for which classical mathematics is unable to provide satisfactory or more concrete answers; where the tools and resources provided by it are simply yet to be developed. Along with the above, it is known that there are many systems, whose evolution in time we do not know. This means that we are not certain of the totality of the variables that govern them or how they interact with each other, or we know them, but the relationships that define the dynamics of the system are chaotic in nature, which means essentially - that we cannot predict its evolution in the long term, and we can only do so in a small neighborhood of a given time initially.

In response to these needs, various methods, theories and processes are emerging, such as the Fuzzy Systems, introduced by L. Zadeh, aimed at processing information and data affected by imprecision or non-probability uncertainty. Some of these new measures to give solution to these systems is formed, essentially, by monotonous and continuous measures but not necessarily additive, as, following the fuzzy example, the integral fuzzy, associated to a fuzzy measure, which is a nonadditive operator and is constructed on the order structure on which it is defined and not on the vectorial structure, as is the case of the classical integral of Riemann or Lebesgue.

But without being necessary to arrive at concepts that we can qualify as high level of development, Mathematics is present in all degrees in Engineering in any university in the world. Normally, the subjects of Mathematics are placed in the first years of these degrees. And it is here that from the consortium we have formed, we see that Mathematics and its associated subjects are fundamental elements of engineering education and proficiency in the area is expected. Engineers are required to be analytical and be able to utilize their mathematical toolkit to solve problems that may be ill or well defined depending on the contextual situation of the engineer. Until quite recently the determination of learning was undertaken using face-to-face techniques such as hand written assessments, private and public communication and observation to name but a few. Assessment and program delivery underwent a seed change with the new millennium when Educational Authorities and Professional bodies adapted their validation and accreditation methods to include learning outcomes within programs of study. The assessment techniques within programs altered accordingly to address these requirements and forces have evolved within higher education to increase the on-line presence.

\section{Students' preferences and opinions about Mathematics}

Considering that Mathematics influences all aspects of human life and culture, it would be desirable that any student, at any level, be able to obtain the necessary skills to build his or her knowledge. At the same time, it should be good that teachers were able to provide with skills to promote creative and meaningful teaching-learning situations and activities that encourage students to learn [8]. If we focus on Higher Education, and more specifically on Engineering, we can observe that some authors propose that teacher should emphasize that students develop capacities and skills, as well as stimulate them to think, reason and deduce [9]. In other words, we should not only transmit concepts, formulas, etc., but also provide them, from a functionalist, utilitarian and practical approach, with knowledge that allows them to develop in life, as well as skills that improve their mathematical culture and autonomy in learning [9].

According to some definitions of Mathematics, it is a deductive science that studies the properties of 
abstract entities, such as numbers, geometric figures or symbols and their relationships. An important branch of this is applied mathematics, which deals with the application of mathematics to the resolution of problems in other disciplines, such as physics, biology or economics. However, there are two worrying facts that are generally repeated in most countries. One of them is the refusal to study mathematics. The other is the results obtained in some tests, such as PISA, which in some countries or regions can be described as devastating $[10,11]$.

The concern about the attitude of rejection generated in students towards Mathematics makes the alarms go off and in many cases the role of the teacher and the methodology used in the classes is questioned.

If one analyzes the role of the teacher as a factor that determines the attitude towards Mathematics, one can find that aspects such as sympathy, enthusiasm, closeness, and in short, the attitude of the teacher influence students. According to Caballero, Blanco and Guerrero [12], the attitudes and emotions of future teachers are analyzed with the objective of promoting positive attitudes and beliefs, since as Etxandi [13] points out "these will directly influence the achievement, beliefs and attitudes of their students". Likewise, a study carried out by Hidalgo, Sáez and Palacios [14] shows a notorious influence of the teacher in the attitude of the students, being $10 \%$ in primary school, $17 \%$ in the first year of secondary school and $35 \%$ in the last year. For this reason, it is important that when teaching future teachers, not only are they taught the concepts of mathematics, but also, and even more importantly, the didactics of mathematics (or, in general, didactics). In terms of methodology, many students say that they are bored, distracted or do not like mathematics because of the way they work. Today, there are still centers in which the teacher is the protagonist and the student is a mere reproducer of what he does. However, there are more and more centers in which innovative projects are put into practice, with the teacher being a mere guide and the student being the protagonist who, by means of cooperative, practical work close to him, finds and gives meaning to mathematics [1]. Researches such as those of Chamoso [15] show that "the student's performance is lower with traditional methods than with more practical methods".

This incorporation of what are currently called active methodologies has been fundamental in the formation of the international consortium that we have carried out for the implementation of the EngiMath project.
At the University of the Basque Country, a research study was carried out on the attitude of Primary Education students towards Mathematics [16]. Primary third and sixth year students were surveyed. The data obtained showed that, in relation to the attitude towards Mathematics, $100 \%$ of the students surveyed believed that they are useful and necessary for daily life, curiously stating that they only made use of them when they did their homework or buy in a shop.

However, although this perception of need and usefulness was total for the population, the results on the attitude towards this matter were different, varying towards worse with the course of the years.

Regarding if students do or not like Mathematics, $77 \%$ expressed that they liked the subject as opposed to $23 \%$ (Fig. 1). In this case, it is remarkable the great difference that there is as for the courses, as we can see in Fig. 2, since $73 \%$ of those of 6 th year showed their like while those of 3 rd year are $100 \%$. The preference place that the subject occupies in front of the rest is notorious, being the percentage of students that place Mathematics among one of their favorites $80 \%$ in 3rd year and $40 \%$ in 6 th year, as it is shown in Fig. 3. Likewise, $16 \%$ of 6 th year students would prefer not to learn Mathematics as opposed to $1 \%$ of $3 \mathrm{rd}$ year students, shown in Fig. 4.

This study is in line with others, for example that of Nuñez et al [17], in which it is observed that the perceived competence for learning and achievement in mathematics decreases significantly as students' progress from the first years of Primary school to the last years of Secondary school. According to the authors of the study, this may be found to be related to the attitude of teachers, whereby students become aware of the expectations that their teachers have about their future achievement, as well as with the performance they are obtaining in this area, which confirms their expectations. In addition, it is also pointed out that, once the students' confidence in their own abilities has been lost, this directly affects their own interest in the subject, negative feelings and emotions arise and anxiety increases significantly.

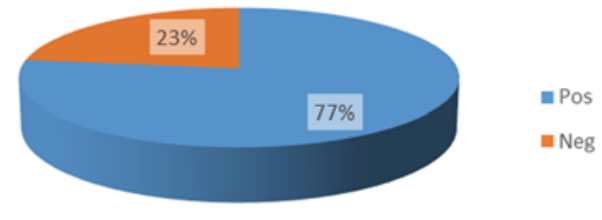

Fig. 1. Positive versus negative opinion expressed by the total surveyed students about Mathematics. 


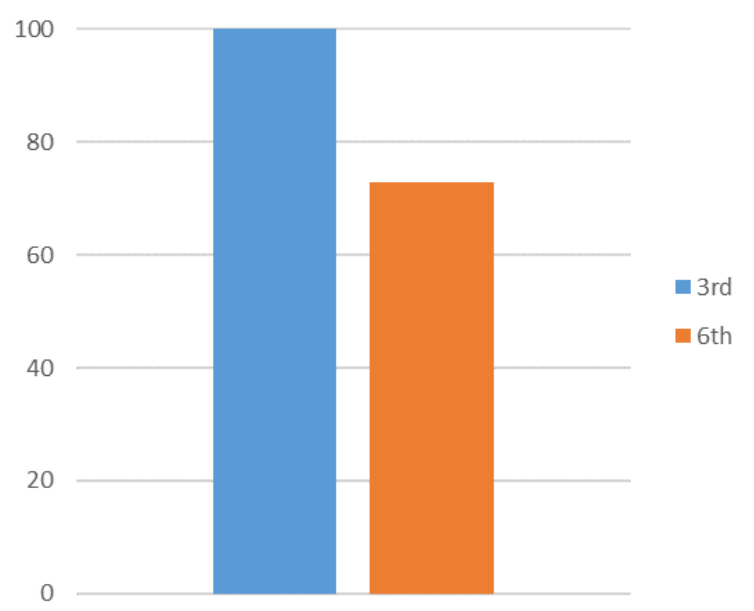

Fig. $2 . \quad$ Opinion about Mathematics: $\mid 100 \%$ of the $3^{\text {rd }}$ year students likes Mathematics.

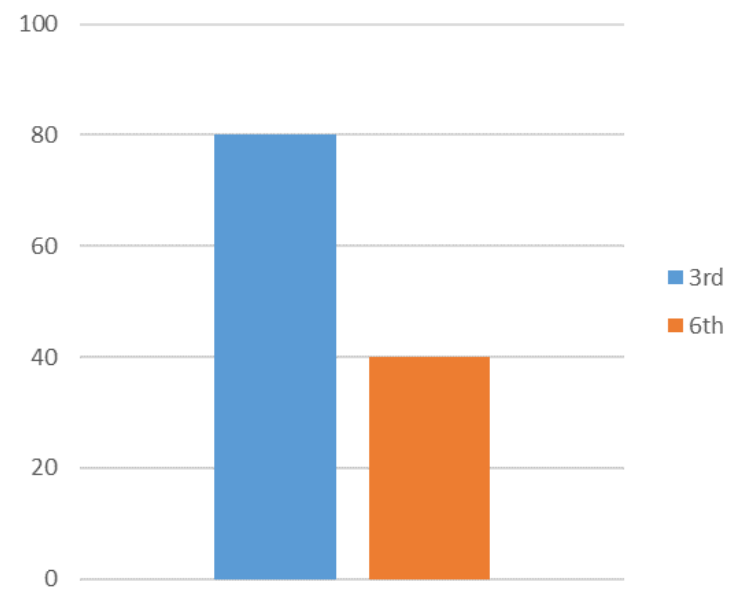

Fig. 3. Is Mathematics one of your favourites subjects? Answers from $3^{\text {rd }}$ and $6^{\text {th }}$ year students.

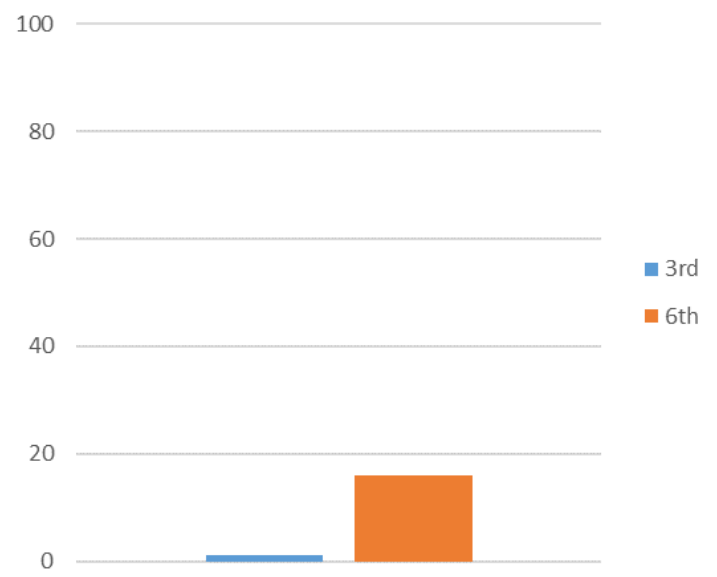

Fig. 4. Students that prefer not to learn Mathematics, in $3^{\text {rd }}$ and $6^{\text {th }}$ year of Primary Education.

Figure 5 clearly shows that as the age of students increases, and even though they are still in Primary
Education, where the difficulty of mathematical concepts is not excessive for most people, the popularity of Mathematics decreases significantly.

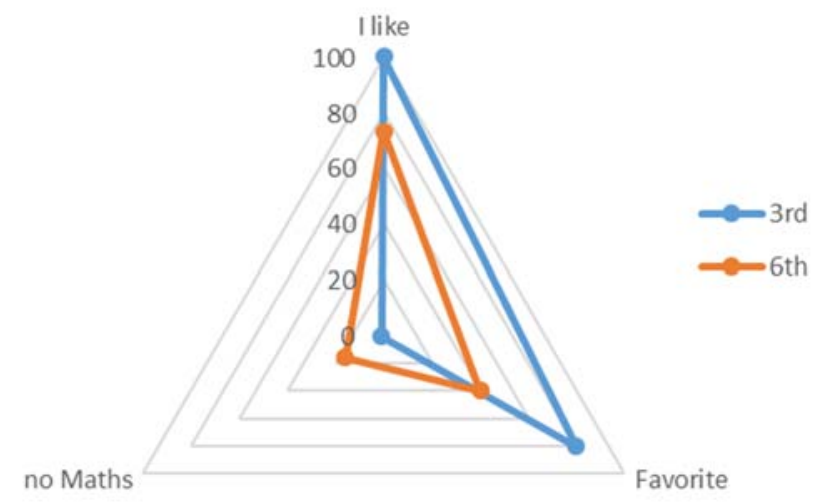

Fig. 5. Comparison of popularity of Mathematics from $3^{\text {rd }}$ to $6^{\text {th }}$ year of Primary School.

From the EngiMath project we want to try to reduce this potential negative feeling through a model that integrates students in the teachinglearning process.

\section{International Consortium of the European Project}

The consortium involves TTK University of Applied Sciences/TTK UAS (Estonia), Letterkenny Institute of Technology/LYIT (Ireland), Polytechnic Institute of Porto/P.PORTO (Portugal), University of the Basque Country/UPV/EHU (Spain), Technical University of Cluj-Napoca/UTC (Romania) and Koszalin University of Technology/PK TUK (Poland). These HEI have been selected based on their identified skills and competencies in engineering mathematics and other core activities and skills required for the project. All HEIs in this project have experience of project participation but this specific partnership will come together for the first time in an official project. All project partners are experienced in implementing ICT and innovative practices in mathematics education and several have been engaged and collaborated in informal projects and knowledge dissemination through conferences, seminars, and staff exchanges. TTK UAS is the coordinator institution of this project. Having been involved in several projects co-financed by different EU programs, this institution has a tight cooperation with Estonian industrial companies and with the Federation of Estonian Engineering Industry. TTK UAS also has a high level of knowledge in on-line learning design. During last 3 years lots of elearning courses of TTK UAS have got the quality 
labels at the Estonian evaluation of e-courses held by HITSA. The award of the best e-learning course of the year 2017 was also given to their e-course. The project participants from TTK UAS, as project coordinators, have a solid background within the core area of this project.

LYIT has expanded the course curriculum to offer over 100 educational programs, many up to Masters level. All programs are designed to combine academic theory with practical skills in order to prepare students for the world of work and lifelong learning and have been developed in conjunction with industry. The Institute was recently voted amongst the top 2 Institutes of Technologies in Ireland in a national survey. LYIT is also actively involved in research, innovation and enterprise development. LYIT project partners were chosen due to previous experience with mathematics on-line assessment systems and on-line learning models, and have also been heavily involved in using ICT in teaching and learning.

P.PORTO ranking fourth among first-choice higher education Portuguese institutions. Featuring 68 undergraduate courses, 60 master's programs, 30 research centres and 18500 students these make up an open, challenging and multicultural community. In formal education, P.PORTO aim is full employment of its graduates and post-graduates and, with that scope, the educational portfolio is continuously aligned with the needs of the business and social world, building strategic cooperation with the local economic agents, and contributing with concrete solutions to real problems. P.PORTO involvement in this project is fundamentally related to the recognized expertise of the participants in the use of new media in higher education and their intense participation in into research activities. Their experience in using Virtual Learning Environments (VLE) in a creative way is particularly valuable in the construction and development of the on-line course.

UPV/EHU offers the highest number of doctorate programs of all Spanish universities, one third of which have received a mention of excellence from the Spanish Ministry of Education. The Spanish Ministry of Science and Innovation has recognized the UPV/EHU as an International Research Campus of Excellence. It has a long experience in several European and International Research Programs. UPV/EHU research team is in the Engineering School of Bilbao. This School has very high-level degrees in Engineering and a long tradition in research and international projects. $\mathrm{UPV} / \mathrm{EHU}$ brings to the project their long-lasting experience in working intensively with methodological design for on-line courses and the implementation of on-line courses.

UTC has Bachelor, Master and Doctoral studies and also offers graduates the opportunity to take part in its life-long learning programs. For its merits, the Technical University of Cluj-Napoca was awarded in 2011 the title of "Advanced Research and Education University" by the Ministry of National Education and has the "High Degree of Confidence" from the Romanian Agency for Quality Assurance in Higher Education. UTC Quality Assurance Department constantly monitors and suggests improvements of the educational process. UTC will oversee all the quality assurance activities in the project.

PK TUK provides education in 27 study courses including civil engineering, economics, arts and humanities. For decades, PK TUK has been a breeding ground for highly qualified personnel in the region. In the year 2014, in the ranking published by the "Perspektywy" education portal, known as the "Prestige with Employers 2014", it obtained the best scores from entrepreneurs from among all the higher education institutions in Zachodniopomorskie Province. PK TUK possesses experienced lecturers, well-developed laboratory facilities with state-of-the-art equipment, a very active academic environment, a wide-ranged grant system and a hot-spot network. PK TUK will contribute to the project with their experience in dissemination activities.

\section{Our Students: Particular Feelings and Perceptions}

Negative attitudes towards Mathematics are widespread among students, affecting very different educational levels, degrees and professional orientations [18]. An obstacle, since, as Álvarez and Ruíz [19] point out, in Higher Education the application of Mathematics encompasses careers linked to science and engineering, as well as those related to Social Sciences. In engineering, although many other skills are needed such as teamwork or communication, technical skills in Mathematics continue to form the basis of the training of engineers. It should be assumed, therefore, a high interest and competence in students who decide to enroll in this Degree. However, research reveals high numbers of suspense, disinterest, frustration, anguish and fear of this subject among students [20]. As mentioned above, teachers can influence the formation of positive or negative attitudes in students. Arguments along these lines show that teachers with negative attitudes use teaching 
methods with their students that foster feelings similar to theirs of insecurity, demotivation, anxiety, lack of knowledge or dislike of the subject [21].

On the contrary, teachers with positive attitudes use methods that encourage initiative and independence, focusing on discovery and provoking in students a taste for and confidence in the subject $[22,23]$.

Within the EngiMath project, we consider that a third way could be to support the study of Mathematics for Engineering through an online model. However, we are aware that the "influence" of the outside is an important factor in the feeling and, consequently, perspective of success. Therefore, a preliminary study has been carried out of the conditions that each member country of the consortium has and what can be some of those influences that could be taken into account when developing a teaching-learning model.

A study of perceptions of the assessment processes in relation to on-line learning and assessment of engineering undergraduates was conducted. The necessity for this analysis is based on outputs from student and academic focus group interviews conducted previously to the "official" constitution of the consortium, in 2016 and 2017 in UK, Ireland and Finland where stakeholders expressed their perceptions, beliefs, knowledge and experiences of on-line assessment systems for engineering mathematics.

The student bases feeding into this study includes not only undergraduate engineering students but also business students from Ireland, Poland, Portugal, Estonia, Finland and Romania. The data from this study will feed directly into the needs assessment and was expanded to include engineering undergraduate students in Spain within this project.

Thus, of the study programs analysed most have on average 20-30 students. There are programs with less students on average, of about 10 students (Geodesy - Estonia, Electrical Engineering Ireland) but also programs with up to 75 students per group (Spain). Both the closeness of the teacher and more individualized treatment are important factors when talking about students' feelings towards a subject. It can also be an important factor to take into account when talking about success rates or the implementation of teaching methodologies.

The gender ratio is of about $65 \%$ male to $35 \%$ female (Fig. 6). There are two exceptions, where the ratio is very similar: Poland and Portugal that have a gender ratio close to 1 to 1 .

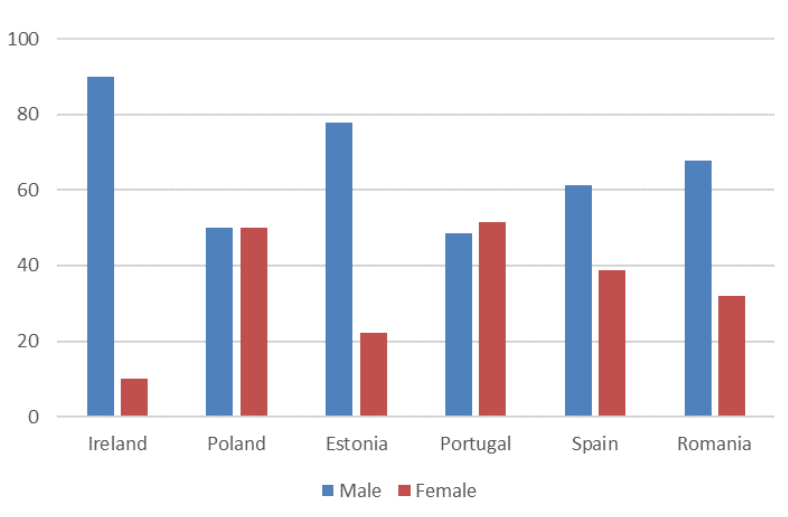

Fig. 6. Gender by country.

The scoring system is different in each country. Even though none of the partners have a pass/fail scoring system, there is a mixture of using percentage and grade systems. The average passing rate is about $60 \%$ on average for all countries with great variations between them. Each country has a different grading system ranging from $40 \%$ to $51 \%$.

Comparison of students' responses displayed startling differences between the countries involved when issues relating to Computer Based Testing (CBT) or on-line assessment were explored.

Students in Ireland report that $80 \%$ of them do not have any exposure to on-line assessment systems prior to entry to third level education. Comparison with Estonia shows that $80 \%$ of their students do have exposure to on-line assessment, whilst approximately $40 \%$ in Poland, Portugal, Spain and Romania have prior experience (Fig. 7).

Students reported on their perceptions of preparedness prior to the use of on-line assessment in third level. The consensus is that they feel prepared in all partner organizations however; many still perceive or experience barriers in relation to the on-line assessment.

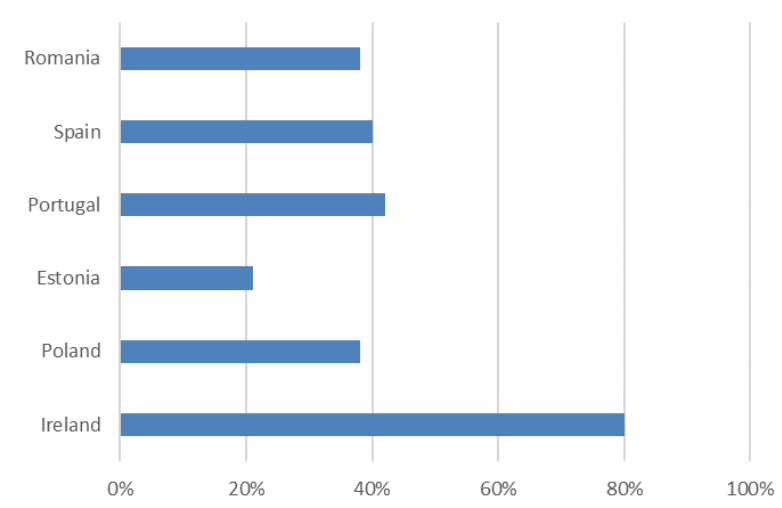

Fig. 7. Students' prior experience with on-line assessment. 
Students' perceptions of their mathematics ability before and after entry to third-level education were analyzed. The majority felt their abilities in mathematics was good, with Spain reporting the highest levels of ability. The majority of perceptions of ability remain constant, but noteworthy is that by second semester of first year that Spanish students' perceptions drop, perhaps due to the difference between the levels of High School and University.

Analysis of expectancy and reward suggests that the majority of students consider their effort is justly rewarded. Spanish students appear to suggest that the reward for work done is not rewarded. This may be the reason why the perceptions of Spanish students regarding their current mathematics abilities have dropped.

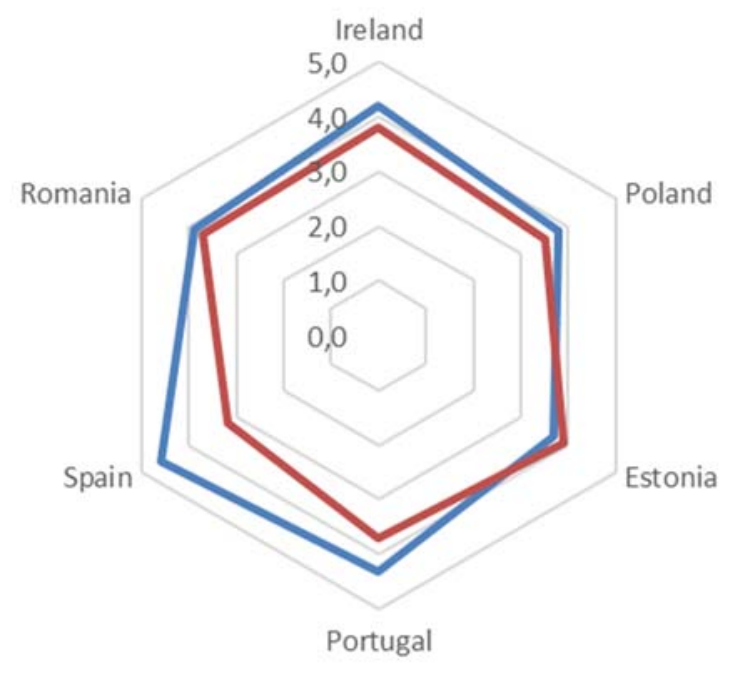

Work needed in Maths $\longrightarrow$ Rewards in Maths

Fig. 8. Students' perceived Effort versus Rewards in Mathematics.

Regarding the role of the teacher, this can go from the most basic evaluator to the critical examiner, guided by external criteria [25]. See also [24] and [26]. As part of the evaluation process, the teacher bears the ultimate responsibility for all decisions leading to different results. The importance of assessment in the context of this study is to determine whether the student's mathematical work corresponds to the characteristics specified by the teacher, and if not, what the obtained level is. Morgan and Watson [24] included equity in the assessment and showed how different assessors can come to different but equally valid assessments. This highlighted fears that are still considered relevant.

It may not be possible to remove all forms of inequity in assessment however, insight and understanding through critical reflection of assessment practices, policies and procedures, has potential for mitigating the effects on students. These specific questions related to the effectiveness of e-assessment will be discussed and scrutinized in a future work.

\section{Conclusion}

At different levels and in different ways, Mathematics is a science that is used daily and by all people. Apart from its intrinsic usefulness for any person, Mathematics is also a fundamental tool for the development, implementation and understanding of subjects in degrees such as Engineering. We cannot understand studying any degree in Engineering without a previous study of Mathematics subjects that provide the basis for the subsequent teaching of other subjects.

However, traditionally Mathematics has had a aura of difficulty and it has been a non-friendly subject for students. For different reasons, the general population have relevant difficulties in understanding and using mathematical knowledge. With the aim of helping to overcome these obstacles in our students of first courses of Engineering degrees, six European universities have formed a research consortium to create on-line learning model in engineering education in order to learn Mathematics.

The progressive and generalized lack of student participation in the teaching and learning process of Mathematics, for different reasons, has a direct impact on the personal effort made in this subject. This circumstance deepens the negative effects of the results in Mathematics because it is one of the most difficult subjects to teach and learn due to the nature of its own content. To alleviate this problem as much as possible, the consortium is creating materials to help overcome these barriers.

The main objective of the project is to explore and develop a shared and common understanding of Mathematics and related problems, within Engineering, in the early stages of Higher Education, and to raise awareness in this regard.

\section{Acknowledgment:}

This work has been funded through the EU ERASMUS+ Programme - Strategic Partnerships (Key Action 2) Agreement Number 2018-KA20307 - Project Reference: 2018-1-EE01-KA203047098. All materials created during the project will 
be open to all on EngiMath website at https://sites.google.com/tktk.ee/engimath/home.

\section{References:}

[1] C. Varela, O. García, E. Bravo, C. Rebollar, J. Bilbao, Introducing Problem Based Learning in Engineering Calculus, For the learning of mathematics 39(2), July 2019, pp. 32-35.

[2] M. Calvo, in Spanish: Enseñanza eficaz de la resolución de problemas en matemáticas, Revista Educación, vol.32, núm. 1, 2008, pp. 123-138.

[3] M. Tesouro, in Spanish: La metacognición en la escuela: la importancia de enseñar a pensar, Educar, vol.35, 2005, pp. 135-144.

[4] O. M. Troncoso, in Spanish: Estrategias metacognitivas en el aprendizaje de las matemáticas: una intervención en el aula para determinar las implicaciones de la implementación de estrategias metacognitivas en el aprendizaje de las matemáticas, $2^{\circ}$ Congreso Internacional de Educación Abrapalabra "Educación, emprendimiento y desarrollo humano", Ibagué (Spain), 19-21 September 2013.

[5] G. Schraw, Promoting General Metacognitive Awareness, in Hope Hartman (ed.), Metacognition in Learning and Instruction: Theory, research and practice, New York, Kluwer Academic Publishers, 2001, pp. 3-16.

[6] C. Varela, C. Rebollar, O. García, E. Bravo, J. Bilbao, Skills in computational thinking of engineering students of the first school year, Heliyon, Volume 5, Issue 11, November 2019.

[7] S. Osses, S. Jaramillo, in Spanish: Metacognicion: un camino para aprender a aprender, Estudios Pedagógicos, vol. XXXIV, no. 1,2008 , pp. 187-197.

[8] O. Gilberto, J. J. Múnera, in Spanish: Las situaciones problema como estrategia para la conceptualización matemática, Educación y Pedagogía, vol.15, no.35, 2003, pp. 183-200.

[9] M. Rigo, D. Páez, B. Gómez, in Spanish: Prácticas metacognitivas que el profesor de nivel básico promueve en sus clases ordinarias de matemáticas. Un marco interpretativo, Enseñanza de las Ciencias, vol. 28, no. 3, 2010, pp. 405-416.

[10] Organisation for Economic Co-operation and Development. PISA 2015 Results (Volume I):
Excellence and Equity in Education. Paris: PISA, OECD Publishing, 2016.

[11] Organisation for Economic Co-operation and Development. PISA 2015 Assessment and Analytical Framework: Science, Reading, Mathematics and Financial Literacy. Paris: PISA, OECD Publishing, 2016.

[12] Caballero, A., Blanco, L. and Guerrero, E. Las actitudes y emocion es ante las Matemáticas de los estudiantes para Maestros de la Facultad de Educación de la Universidad de Extremadura. Simposio de Investigación y Educación Matemática, 2007.

[13] Etxandi, R. Matemática en educación primaria: un intento de renovación de la práctica en el aula. Uno: Revista de didáctica de las matemáticas, n. 45, 2007, pp. 15-25

[14] Hidalgo, S., Maroto, A., Palacios, A. ¿Por qué se rechazan las matemáticas? análisis evolutivo y multivariante de actitudes relevantes hacia las matemáticas. Revista de educación, $\mathrm{n}^{\circ} 334$, 2004, pp. 75-95

[15] Chamoso, J. Evolución de las actitudes ante la enseñanza-aprendizaje de las matemáticas en la Educación Primaria y Secundaria Obligatoria. Análisis de las causas que inciden dicha actitud, 1998.

[16] J. Ruiz de Gauna Gorostiza, J. García Iturrioz, J. Sarasua Fernández, "Perspectiva de los alumnos de Grado de Educación Primaria sobre las Matemáticas y su enseñanza", Números. Revista de Didáctica de las Matemáticas, vol. 82, pp. 5-15, March 2013.

[17] J. C. Núñez, J. A. González-Pienda, L. Alvarez, P. González, S. González-Pumariega, C. Roces, L. Castejón, P. Solano, A. Bernardo, D. García, E. Helena da Silva, P. Rosário, L. do Socorro Rodrigues Feio, "Las actitudes hacia las Matemáticas: perspectiva evolutiva", Proceedings of VIII Congreso GalaicoPortugués de Psicopedagoxía, pp. 2389-2396, Braga: Universidade do Minho, 2005.

[18] García, M. and Juárez, J. Revisión del Constructo actitud en Educación Matemática: 1959-1979. Revista Iberoamericana de Educación Matemática, 26, 2011, 117-125.

[19] Álvarez, Y. and Ruíz, M. Attitudes toward mathematics among engineering students at Venezuelan autonomous universities. Revista de Pedagogía, 31(89), 2010, 225-249. 
[20] Swars, S.; Daane, C. J. and Giesen, J. Mathematics anxiety and mathematics teacher efficacy: What is the relationship in elementary preservice teachers? School Science and Mathematics, 106(7), 2010, 306-315.

[21] Bates, A. B., Latham, N. and Kim, J. Linking Preservice Teachers Mathematics Self-Efficacy and Mathematics Teaching Efficacy to Their Mathematical Performance. School Science and Mathematics, 111(7), 2011, 325-333.

[22] Castelló, M.J.; Codina, R. and López, P. Cambiar las actitudes hacia las Matemáticas resolviendo problemas. Una experiencia en Formación del Profesorado de Educación Primaria. Revista Iberoamericana de Educación Matemática, 22, 2010, 65-76.

[23] Sakiz, G., Pape, S. J. and Hoy, A. W. Does perceived teacher affective support matter for middle school students in mathematics classrooms? Journal of School Psychology, 50(2), 2012, 235-255.

[24] Zacharoula Smyrnaiou, Menelaos Sotiriou, Sofoklis Sotiriou, Eleni Georgakopoulou, Multi- Semiotic Systems in STEMS: Embodied Learning and Analogical Reasoning Through a Grounded- Theory Approach in Theatrical Performances, WSEAS Transactions on Advances in Engineering Education, Volume 14, 2017, pp. 99-112

[25] C. Morgan and A. Watson. The Interpretative Nature of Teachers' Assessment of Students' Mathematics: Issues for Equity. Journal for Research in Mathematics Education, vol. 33, no. 2, 2002, pp. 78-110. https://doi.org $/ 10.2307 / 749645$

[26] Horng-Jinh Chang, Whe-Min Wang, Comparisons of Students'stress Source in Different Countries, WSEAS Transactions on Advances in Engineering Education, Volume 14, 2017, pp. $90-98$ 